\title{
Complexidade e transdisciplinaridade em educação: cinco princípios para resgatar o elo perdido*
}

\author{
Akiko Santos \\ Universidade Federal Rural do Rio de Janeiro, \\ Laboratório de Estudos e Pesquisas Transdisciplinares
}

\section{Introdução}

A teoria da complexidade e transdisciplinaridade surge em decorrência do avanço do conhecimento e do desafio que a globalidade coloca para o século XXI. Seus conceitos contrapõem-se aos princípios cartesianos de fragmentação do conhecimento e dicotomia das dualidades (Descartes, 1973) e propõem outra forma de pensar os problemas contemporâneos.

A fragmentação do conhecimento, que se generaliza e se reproduz por meio da organização social e educacional, tem também configurado o modo de ser e pensar dos sujeitos. A teoria da complexidade e transdisciplinaridade, ao propor a religação dos saberes compartimentados, oferece uma perspectiva de superação do processo de atomização.

Como uma teoria pedagógica, a complexidade e a transdisciplinaridade encontram-se ainda na fase de

* Este texto é uma versão revista e ampliada da comunicação apresentada no I Encontro Brasileiro de Estudos da Complexidade (EBEC), Curitiba, 11 a 13 de julho de 2005, com o título Princípios orientadores para reencantar a educação. construção, no entanto, já se nota um grande número de educadores que recorrem a seus conceitos, como também se observam núcleos de docentes-pesquisadores nas universidades começando a se organizar nos níveis local e nacional.

Em razão tanto do surgimento de novas teorias pedagógicas como da reconfiguração das já existentes, Libâneo (1991, 2005), sempre preocupado em oferecer aos professores sínteses classificatórias das teorias pedagógicas que fundamentam as práticas docentes, elaborou uma nova classificação. Reproduzse, a seguir, tal classificação, para que o leitor possa se situar, atentando para a dinâmica de disjunção e conjunção das teorias já conhecidas pelos professores, e as emergentes, decorrentes da transformação socioeconômica e da renovação cultural.

No interior da corrente que Libâneo classifica como "holística" está a teoria da complexidade, objeto do presente texto. A diversidade de modalidades apontada nessa corrente reflete a variedade de construções em relação ao contexto contemporâneo, o holismo propriamente dito, a teoria naturalista do conhecimento, a ecopedagogia e o conhecimento em 
Quadro 1 - Correntes pedagógicas contemporâneas

\begin{tabular}{|l|l|}
\hline Correntes & Modalidades \\
\hline Racional-tecnológicas & $\begin{array}{l}\text { Ensino de excelência } \\
\text { Ensino tecnológico }\end{array}$ \\
\hline Neocognitivistas & $\begin{array}{l}\text { Construtivismo pós-piagetiano } \\
\text { Ciências cognitivas }\end{array}$ \\
\hline $\begin{array}{l}\text { Sociologia crítica do currículo } \\
\text { Teoria histórico-cultural } \\
\text { Teoria sociocultural } \\
\text { Teoria sociocognitiva } \\
\text { Teoria da ação comunicativa }\end{array}$ \\
\hline "Holísticas" & $\begin{array}{l}\text { Holismo } \\
\text { Teoria da complexidade } \\
\text { Teoria naturalista do conhecimento } \\
\text { Ecopedagogia } \\
\text { Conhecimento em rede }\end{array}$ \\
\hline Pós-estrutruralismo \\
Neopragmatismo
\end{tabular}

Fonte: Libâneo, 2005, p. 30.

rede. Aranha (1996) identificava suas características nomeando-as de paradigmas emergentes, e Gadotti (2003) chamou-os de paradigmas holonômicos.

A intenção do presente texto é mais pontual. Pretende-se realçar alguns dos seus princípios e discutir o potencial que eles têm para resgatar o elo perdido com a prática de fragmentação do conhecimento.

A atual estrutura educacional, sedimentada com base em princípios seculares, tem levado os docentes a uma prática de ensino insuficiente para uma compreensão significativa do conhecimento, e muitas vezes suas respostas não satisfazem aos alunos, que perguntam: "por que tenho que aprender isso?".

Embora concebidas separadamente, a complexidade (também chamada de pensamento complexo) e a transdisciplinaridade articulam-se. Se vistas separadamente, uma torna-se princípio da outra. O pensamento complexo foi sistematizado por Edgar Morin (1991), e a transdisciplinaridade, por Basarab Nicolescu (1999).

Ao servirem de instrumentos para a observação da realidade, seus princípios revelam a defasagem conceitual da prática educacional, realçando as concepções ancestrais tácitas na estrutura social, cultural- mental da sociedade moderna. A teoria da complexidade e transdisciplinaridade sugere a superação do modo de pensar dicotômico das dualidades (sujeitoobjeto, parte-todo, razão-emoção etc.) proveniente da visão disseminada por Descartes (1973), estimulando um modo de pensar marcado pela articulação.

$\mathrm{Na}$ prática do magistério, esse novo referencial representa mudança epistemológica e vem sugerindo reconceitualizações de categorias analíticas, de vez que, pelas orientações dicotômicas das dualidades, se valorizou somente uma das dimensões de tais dualidades: pela dicotomia inicial sujeito-objeto, houve a supervalorização da objetividade e da racionalidade, como também se seguiu a orientação de descontextualização, simplificação e redução quando o fenômeno é complexo, em detrimento da dimensão oposta, igualmente integrante dos fenômenos, que compreende a subjetividade, a emoção, a articulação dos saberes disciplinares e o contexto.

Os princípios que fundamentam as organizações sociais, culturais, educacionais se apóiam, basicamente, na recomendação de Descartes (1973, p. 46), segundo a qual, quando um fenômeno é complexo, se deve "dividir cada uma das dificuldades [...] em tantas parcelas quantas possíveis e quantas necessárias fossem para melhor resolvê-la".

Esse é o princípio da fragmentação. Como conseqüência dele, a prática pedagógica tendeu a organizar-se nos moldes da disjunção dos pares binários: simples-complexo, parte-todo, local-global, unidadediversidade, particular-universal; em contrapartida, cristalizou-se a subdivisão do conhecimento em áreas, institutos e departamentos, cada qual delimitado pelas fronteiras epistemológicas. Cada instituto ou departamento organiza seus respectivos cursos por meio de listas de diferentes disciplinas. São as grades curriculares que, na prática, funcionam como esquemas mentais ao impedirem o fluxo de relações existentes entre as disciplinas e áreas de conhecimento. Por exemplo, a didática, como disciplina, é tratada separadamente da disciplina filosofia. Vigorando o princípio da fragmentação, da divisão, da simplificação, da redução, tem-se como conseqüência a descontextualização do agir pedagógico, passando a didática a 
ser uma disciplina apenas técnica, por meio da qual se aprende o uso de técnicas didáticas.

Essa visão descontextualizada e simplificadora, difundida pela ciência moderna, tornou-se hegemônica ao longo dos últimos 400 anos e manteve latente a questão da complementaridade dos pares binários. A partir das últimas décadas, no entanto, o que permanecia implícito se manifesta com força significativa e se transforma em princípios científicos, evolução acontecida no próprio seio da ciência moderna. Ainda que alguns autores considerem esse novo olhar como algo exótico (Carvalho, 2003), já não se pode mais ignorar a penetração, na vida acadêmica, da articulação dos pares binários e da conectividade dos saberes (Morin, 2001).

Não há dúvida de que o princípio de fragmentação acumulou conhecimentos, ocasionando um verdadeiro boom tecnológico hoje altamente visível e vivenciado. No entanto, no cerne desse progresso vemse praticando um outro tipo de relação com o conhecimento, na forma de rede de relações, o que sugere mudança conceitual e princípios mais adequados ao estágio atual de desenvolvimento da ciência.

Entre esses novos princípios, aquele que tem tido larga aceitação é o chamado holográfico que, ao fazer o movimento de volta à contextualização, reconhece que o todo não é somente a simples soma das partes (fatoração mecânica). Segundo Morin (1991, p. 123), a soma do conhecimento das partes não é suficiente para se conhecer as propriedades do conjunto, pois o todo é maior do que a soma de suas partes. Além disso, quando se toma o todo não se vê a riqueza das qualidades das partes, por ficarem inibidas e virtualizadas, impedidas de expressarem-se em sua plenitude. Daí que o todo é menor do que a soma de suas partes. As relações das partes com o todo são dinâmicas, portanto, o todo é, ao mesmo tempo, menor e maior que a soma das partes.

\section{Princípio holográfico}

Esse princípio afirma que a parte não somente está dentro do todo, como o próprio todo também está dentro das partes (Morin, 1991). Ressalte-se, com isso, o paradoxo do uno e do múltiplo, ou seja, da íntima relação e interdependência entre os dois termos que se polarizaram na era moderna. Assim, o princípio holográfico remete à articulação dos pares binários: parte-todo, simples-complexo, local-global, unidadediversidade, particular-universal.

Como observou Petraglia (1995), com a disjunção desses termos na modernidade houve perda de significação do conhecimento. Os princípios da disjunção e da simplificação concretizam-se na educação por meio de uma estrutura disciplinar do conhecimento. Seguindo as orientações cartesianas, concretizadas na estruturação disciplinar do conhecimento, o professor crê que a soma das partes listadas nas grades curriculares (estruturadas por meio de uma sequiência de múltiplas disciplinas compartimentadas) significa o todo do conhecimento.

Essa norma curricular tem provocado a incapacidade de estabelecer relações entre os conhecimentos obtidos. Como conseqüência dessa estrutura curricular, os alunos saem do curso com uma cabeça bem cheia (Morin, 2000) de conhecimentos justapostos.

Segundo David Bohm (1980), muitos dos nossos problemas se devem à tendência de fragmentar 0 mundo e ignorar a interligação dinâmica entre todas as coisas, desconhecendo o fato de que o universo é constituído como um holograma. Ou seja, tudo no universo faz parte de um contínuo, que, por conta da sua natureza ativa e dinâmica, o autor chama de holomovimento.

Karl Pribram (apud Talbot, 1991), neurofisiologista da Universidade de Stanford, estudando o cérebro, chegou às mesmas conclusões de David Bohm, físico quântico, definindo o cérebro como um holograma envolto por um universo holográfico.

A visão holográfica abre nova perspectiva aos pesquisadores da área educacional. Não se trata somente de inverter o foco do binário parte-todo, mas de acrescentar o movimento de religação ao conjunto desmontado, à totalidade fragmentada. Trata-se de atuar em duas direções opostas: contexto e unidade simples (todo e parte), estabelecendo a interligação dinâmica. 
A contextualização é necessária para explicar e conferir sentido aos fenômenos isolados. As partes só podem ser compreendidas a partir de suas inter-relações com a dinâmica do todo, ressaltando-se a multiplicidade de elementos interagentes que, na medida da sua integração, revela a existência de diversos níveis da realidade, abrindo a possibilidade de novas visões sobre a mesma realidade.

Assim, a representação de conhecimento como uma árvore, consagrada por Descartes e ainda hoje utilizada, torna-se inadequada por sua separação em ramos e pelas hierarquizações estanques que a imagem sugere. Hoje, propõe-se rizoma (Deleuze \& Guattari, 1980) como representação do conhecimento implicado. Uma rede de conexões mutuamente implicadas.

Ante a nova metáfora de conhecimento em rede, representada por uma raiz, uma raiz rizomática (interconectada), o nosso modo de ensinar e a nossa atitude conceitual revelam-se desarticulados e insuficientes, por seu enfoque concentrado no racional e por ignorarem o contexto relacional entre o todo e as partes. Uma vez percebidas as relações entre o todo e as partes, revela-se o sentido do conhecimento para a vida: o elo perdido.

Assim como a imagem do cérebro como um holograma sugerida por Pribram, no processo de aprendizagem a compreensão do significado de uma frase evoca, instantaneamente, imagens, sons, vivências, conhecimentos adquiridos em diversas disciplinas, instâncias e momentos da vida, intuições, sensações, humores, sentimentos de simpatia ou antipatia, sentimentos de cooperação ou de rejeição. As realidades objetiva e subjetiva são complexas e interativas. No entanto, ignorando a dinâmica de interação, o professor prioriza determinado conteúdo na expectativa de que os alunos o absorvam recorrendo à memorização.

A construção de conhecimento, segundo Morin (1998), apóia-se nos movimentos retroativos e recursivos. O autor atenta para o fato de que não há uma única maneira de aprender. $\mathrm{O}$ processo cognitivo é um processo complexo, uma vez que o sujeito vê o objeto em suas relações com outros objetos ou acon- tecimentos. As relações cerebrais estabelecem-se entretecendo-se em teias, em redes. Como observou Machado (1999, p. 138), "a idéia de conhecer assemelha-se à de enredar".

O princípio holográfico coloca aos professores o dilema posto pelas estruturas disciplinares e fragmentárias do ensino. Dilema que os obriga a se exercitarem na transdisciplinaridade, termo cunhado por Jean Piaget, que chegou inclusive a afirmar que, um dia, a interdisciplinaridade seria superada por transdisciplinaridade (Nicolescu, 2003).

\section{Princípio da transdisciplinaridade}

A transdisciplinaridade tem sua origem no teorema de Gödel, autor que, em 1931, propôs distinguir vários níveis de realidade, e não apenas um nível, como entende o dogma da lógica clássica (Mello, 1999). Com a comprovação na física quântica, tal proposição provocou um escândalo quando demonstrou que o quanton é composto simultaneamente de ondas e corpúsculos, e que, no nível do quanton, a contradição entre onda e corpúsculo desaparece, constituindo uma unidade.

A partir dessa descoberta, a lógica clássica entra em crise, abalada em seu fundamento centrado na nãocontradição. A transdisciplinaridade propõe-se a transcender a lógica clássica, a lógica do "sim" ou "não", do "é" ou "não é", segundo a qual não cabem definições como "mais ou menos" ou "aproximadamente", expressões que ficam "entre linhas divisórias" e "além das linhas divisórias", considerando-se que há um terceiro termo no qual "é" se une ao "não é" (quanton). E o que parecia contraditório em um nível da realidade, no outro, não é.

Conforme Nicolescu (1999, p. 29), em termos matemáticos, a lógica clássica expressa-se da seguinte forma:

1. O axioma da identidade: A é A;

2. O axioma da não-contradição: A não é não-A;

3. O axioma do terceiro excluído: não há um termo $\mathrm{T}$, que é, ao mesmo tempo, A e não-A. 
Por esses axiomas, a lógica clássica admite um único nível de realidade, uma vez que o axioma número 3 exclui a possibilidade de articulação. A lógica quântica introduz inovações, definindo um terceiro termo incluido: "Há um terceiro termo T, que, ao mesmo tempo, é A e não-A" (Nicolescu, 1999, p. 29). Ao articular, o terceiro termo incluído sempre leva a um outro nível de realidade, diferente do nível anterior da lógica da não-contradição, abrindo a possibilidade de uma nova visão da realidade.

Como processo, a lógica do terceiro termo incluído sempre pressupõe o aparecimento de outros elementos contrapondo-se em qualquer nível de realidade. Trata-se de um processo sem fim. Nesse sentido, não se tem uma Verdade última e absoluta, mas verdades sempre relativas e passíveis de mudanças no decorrer do tempo.

Assim, a transdisciplinaridade significa transgredir a lógica da não-contradição, articulando os contrários: sujeito e objeto, subjetividade e objetividade, matéria e consciência, simplicidade e complexidade, unidade e diversidade (idem). Ao articular esses pares binários, por meio da lógica do terceiro termo incluído, a compreensão da realidade ascende a outro nível, tomando um significado mais abrangente e sempre em aberto para novos processos.

Recomendados nos Parâmetros Curriculares Nacionais (PCNs) (Brasil, 2001), os temas transversais recorrem a essa lógica quando articulam os conhecimentos das diversas disciplinas. Os temas transversais, tendo em vista um tema social, transgridem as fronteiras epistemológicas de cada disciplina, possibilitando uma visão mais significativa do conhecimento e da vida.

Na medida do viável, os temas transversais resgatam as relações existentes entre os conhecimentos. Outra forma de evidenciar e trabalhar as conexões entre os conhecimentos pode ser a realização periódica de jornadas temáticas, a exemplo da realizada na França, em 1998, sob a direção de Edgar Morin (2001), reunindo professores para apresentar trabalhos que rejuntavam os saberes em torno de proble- mas essenciais. É somente um exemplo de como se pode mobilizar dentro da estrutura tradicional.

Ao trabalhar com a multirreferencialidade do conhecimento, o princípio que rege os temas transversais muda o conceito de conhecimento. Passa-se da disciplinaridade (lógica clássica) à transdisciplinaridade (lógica do terceiro termo incluído). O conhecimento é concebido como uma rede de conexões (do arbóreo passa-se ao conceito rizomático), o que leva à multidimensionalidade do conhecimento e à distinção de vários níveis de realidade.

Assim, a multidimensionalidade diz respeito ao reconhecimento dos diferentes níveis de realidade no processo cognitivo. Abertura que se dá conforme os tipos de observadores, cujas percepções, quando ampliadas por variadas articulações, possibilitam um conhecimento cada vez mais significativo e abrangente.

O conhecimento transdisciplinar associa-se à dinâmica da multiplicidade das dimensões da realidade e apóia-se no próprio conhecimento disciplinar. Isso quer dizer que a pesquisa transdisciplinar pressupõe a pesquisa disciplinar, no entanto, deve ser enfocada a partir da articulação de referências diversas. Desse modo, os conhecimentos disciplinares e transdisciplinares não se antagonizam, mas se complementam.

Diferente do enfoque tradicional-disciplinar, a pesquisa transdisciplinar traz à tona uma multiplicidade fantástica dos modos de conhecimento. Sua preocupação com os níveis de realidade (superando a dimensão única que a pesquisa disciplinar enfatiza) e com a idéia de totalidade a leva a aceitar a causalidade concebida como em circuito e multirreferencial, em vez de prender-se a uma realidade linear e unidimensional (Congresso de Locarno, 1997).

Por sua vez, para revelar-se, a complexidade dos fenômenos exige do observador uma postura transdisciplinar. Ou seja, para ser conhecido em toda a sua dimensão conectiva, o objeto exige conhecimentos e observadores transdisciplinares.

Aplicados ao processo ensino-aprendizagem, os princípios holográfico e transdisciplinar tornam o 
aprender uma atividade prazerosa na medida em que resgatam o sentido do conhecimento (perdido em razão de sua fragmentação e descontextualização). Esse é o desafio que se coloca na reconstrução da prática pedagógica.

Para fazer frente a tal desafio, há que se deslocar para um outro ponto de vista - como diz Boff (1997, p. 9), "todo o ponto de vista é a vista de um ponto". Isto é, torna-se necessário passar do conceito dicotômico (parte-todo, ser-saber) para a construção de um conceito articulado, um pensar que considere o ser como sinônimo do saber, o saber como uma razão de ser, uma relação simbiótica, e não dicotômica como na pedagogia tradicional. Pedagogia que separa o sujeito do conhecimento, considerando o saber como algo objetivo, neutro e nobre, em detrimento da dimensão subjetiva, dimensão esta que, no dizer de Descartes (1973, p. 143), é "fonte de idéias confusas".

A transdisciplinaridade exige também uma postura de democracia cognitiva (todos os saberes são igualmente importantes), superando o preconceito introduzido pela hierarquização dos saberes. Em razão dessa hierarquização, tem-se como senso comum a crença segundo a qual são nobres os conhecimentos da área das ciências exatas, enquanto os das ciências humanas são "abobrinhas". Essa banalização requer uma mudança conceitual quanto ao conhecimento: não mais concebê-lo como neutro, estático, universal e imutável, adquirível mediante memorização, mas concebê-lo como histórico, não-neutro, dinâmico e provisório (Aragão, 1993). O conhecimento nunca é definitivo, mas um produto da humanidade, estando sempre ligado a circunstâncias históricas, que são dinâmicas como o são os indivíduos que o vivenciam e o projetam.

Esse novo olhar da transdisciplinaridade traz ainda um desafio maior: o de transitar pela diversidade dos conhecimentos (biologia, antropologia, física, química, matemática, filosofia, economia, sociologia). Isso requer espírito livre de preconceitos e de fronteiras epistemológicas rígidas. Esse é um dos problemas que a prática da interdisciplinaridade (Fazenda, 1993, 2001) tem enfrentado. Mudança conceitual re- quer mudança de posturas. Se a atitude não acompanha as mudanças conceituais, o resultado poderá ser uma interdisciplinaridade apenas pontual.

Em virtude da formação de tipo disciplinar, os professores que enfrentam o desafio da transdisciplinaridade estão sujeitos a ambigüidades e contradições que vão sendo corrigidas e adequadas na medida do aprofundamento conceitual e, principalmente, da autocrítica entre os pares. Essa mudança atitudinal condiciona-se à mudança epistemológica: mudar um determinado conceito exige, por sua vez, mudanças de outros co-relacionados, dando lugar a uma rede de conceitos (sistema).

Na prática educativa, os professores desconsideram o princípio holográfico e o princípio da transdisciplinaridade, separando a parte do todo, dando um tratamento mecânico ao conhecimento. Os professores dedicam-se a explicações exaustivas em definições, conceitos, fórmulas, e fazem uso da linguagem voltada para a racionalidade tecnocientífica. A fragmentação traz como conseqüência a idéia de neutralidade e objetividade do conhecimento. Com esse viés, o conhecimento referido em sala de aula perde sentido existencial ao não trabalhar a relação com o todo e com o sujeito do processo cognitivo.

A transdisciplinaridade maximiza a aprendizagem ao trabalhar com imagens e conceitos que mobilizam, conjuntamente, as dimensões mentais, emocionais e corporais, tecendo relações tanto horizontais como verticais do conhecimento. Ela cria situações de maior envolvimento dos alunos na construção de significados para si. Os alunos "constroem" conhecimentos, como diz Paulo Freire (1997). Trabalhar a educação com tal visão supera a mesmice do padrão educativo, encanta o aprender e resgata o prazer de aventurar-se no mundo das idéias.

\section{Princípio de complementaridade dos opostos}

Conceber o conhecimento a partir da visão holográfica, pela transdisciplinaridade, leva ao entrelaçamento desses olhares com o princípio de complementaridade dos opostos, de Niels Bohr (1961). Prê- 
mio Nobel de Física em 1922, ao desenvolver a teoria da relatividade e da mecânica quântica, esse cientista propôs a noção de complementaridade buscando resolver impasses em torno da questão das unidades subatômicas, afirmando então que onda e partícula são dimensões integrantes de uma mesma realidade.

A partir dessa mudança de percepção, o conceito de complementaridade passou a ser usado para descrever os fenômenos da natureza. Para a geração de físicos daquela época não foi fácil passar aos novos conceitos sugeridos pela teoria quântica. Relutou-se muito em abandonar velhos conceitos da física clássica (Heisenberg, 1996).

Assim como não foi fácil a mudança conceitual para aqueles físicos, o homem também enfrenta um ambiente que reproduz velhos conceitos, e ele próprio é educado nos moldes duais, interpretando o mundo em termos polares e reducionistas.

Ao articular os opostos, o princípio da complementaridade opõe-se à dicotomia dos binários, remetendo o olhar para o nível de realidade integrada, isto é, razão "e" emoção, indivíduo "e" sociedade, saúde "e" doença, subjetivo "e" objetivo, sapiens "e" demens, bem "e" mal, clausura "e" abertura das crenças ou das teorias. Impõe-se colocar a conjunção "e" para significar a junção, a associação, a articulação desses pares.

Dicotomizar e exaltar apenas uma das características dos binários (por exemplo racionalidade e objetividade) como base do ensino tem levado a incompreensões do processo de ensino e aprendizagem, justamente pela unilateralidade. Essa polaridade igualmente provoca nas gerações que passaram e continuam a passar por tal sistema a incapacidade de articular as diversas dimensões do seu ser. Na modernidade, ao dicotomizar o binário razão-emoção, a emoção delimitou-se às disciplinas de psicologia e psicanálise.

Resgatar a dimensão emocional não significa supervalorizá-la: nem só razão, nem apenas emoção. O que se está propondo é articular pares binários. Razão sem emoção não capta a característica humana, enquanto emoção sem razão não conduz a parte alguma.
Assim, essa visão de homem e de mundo significa superar o condicionamento experimentado durante o processo de formação do indivíduo sob o princípio da dicotomia, reforçado, ao longo da vida, desde as ameaças (para modelar o comportamento das crianças) com o "bicho-papão" e do "lobo mau"; literaturas infantis dirigidas a cristalizar um pensar dicotomizado, o bem personificado num personagem (Cinderela), e o mal, no outro (madrasta). Tal percepção ainda se reproduz, por exemplo, por certos filmes e novelas da televisão. Esse dualismo também perpassa os noticiários, como testemunhamos nos informativos sobre o conflito entre os Estados Unidos da América e o Iraque. O mal sempre está representado no outro. $\mathrm{O}$ bem e o mal nunca convivem no mesmo sujeito. Cada um representa o mal no outro.

Essa visão dicotômica é absorvida pelos indivíduos e manifesta-se no modo de pensar, sentir, agir e viver. Cada um dos pares binários, dicotomizados, devem ser olhados desde um outro prisma, o da articulação. Quando se muda o ponto de vista obtém-se uma vista diferente, um outro panorama dos fenômenos em observação.

Por exemplo, pode-se, ainda, verificar a simbiose dos opostos no binário ordem-desordem. A busca do homem pela ordem manifesta-se desde os seus primórdios. Os mitos, as religiões, as teorias filosóficas são manifestações dessa procura diante de uma natureza poderosa que, ao mesmo tempo em que lhe dá vida, pode também tirá-la. Nessa relação homemnatureza, a ciência é o ápice da conquista do homem e tem focalizado a ordem nos fenômenos da natureza e da vida. As crenças e teorias dão ao homem uma margem de atuação sobre essa natureza.

A ordem, a repetição, a constância significam segurança para o homem, mas essa invariância leva à degeneração. E, para o homem tomado individualmente, ao tédio e ao embrutecimento. A desordem, o aleatório, a irregularidade, o desvio, o imprevisível, o acaso regenera a vida e a própria ordem, colocando ao homem o desafio da sobrevivência, obrigando-o a construir nova ordem como um permanente processo de revigoramento por meio da construção de novas 
organizações e maneiras de situar-se neste mundo. Ordem e desordem, separadamente, levam ambas à degradação e à degeneração.

No âmbito da gestão educacional, a ordem está representada pela legislação e pela organização, normas legais e burocráticas, grades curriculares. $\mathrm{Na}$ gestão dessa organização surgem a desordem e a ambigüidade, introduzidas pelos sujeitos que dão dinamicidade ao modelo de funcionalidade e racionalidade do sistema. Seres humanos, com sua diversidade, dão suporte e funcionalidade ao gerenciamento da organização. O comportamento das pessoas na instituição é um misto de dependência e autonomia (outro par binário). A ordem é desejável, mas a desordem, o espontaneísmo, a desobediência, proporcionam vitalidade à instituição, embora, em excesso, levem à sua desintegração. Como se vê, há entre ambas uma relação simbiótica de interdependência, os dois termos estão estreitamente associados.

Nesse sentido, pode-se ainda aplicar o princípio da complementaridade ao binário dependência-autonomia. O ser humano é dependente do sistema onde vive, porém, ao manter a sua autonomia como sujeito criativo que está em permanente renovação, introduz comportamentos ambíguos e, muitas vezes, contraditórios em relação às regras estabelecidas pelo sistema.

De acordo com a lógica clássica, as asseverações dos parágrafos anteriores constituem uma irracionalidade por não obedecerem ao axioma da não-contradição, importante nessa lógica. Segundo Morin (1983, p. 131), trata-se de

\footnotetext{
[...] uma noção lógica, é a autonomia que é ao mesmo tempo dependente sem deixar de ser autônoma, é, de certo modo, a necessidade de bastardizar os nossos instrumentos conceptuais e renunciar a um princípio unificador mestre e supremo.
}

Outro conceito profundamente arraigado no imaginário social e repetidamente reforçado pelas novelas televisivas, que sempre terminam em casamento, é a certeza da felicidade na estabilidade matrimonial. Acredita-se que a felicidade está na estabilidade, na certeza e na ordem. Daí a mensagem implícita, "feliz para sempre", ao final de cada novela. Aliás, nada mais falso, considerando-se a natureza instável do homem e da própria vida. Então, há que integrar o princípio da incerteza à certeza que se constrói para orientar as ações do dia-a-dia.

\section{Princípio da incerteza}

O conceito de incerteza contrapõe-se às mensagens dualistas dicotomizadas, que priorizam somente a dimensão que contribui para a construção da ordem, da certeza, tornando-se uma visão parcial, reducionista, determinista e objetivista. Esse é o conceito disseminado pela ciência moderna e pelo método científico de comprovação. Ao considerar o princípio de complementaridade dos opostos, necessariamente entra em questão a articulação das dualidades (no caso, certeza e incerteza), e não a sua dicotomização.

Esse princípio tem origem na elaboração matemática de Werner Heisenberg (1962). Prêmio Nobel de Física em 1932, esse autor demonstrou que o comportamento das partículas é totalmente imprevisível. Ao deparar-se com a impossibilidade em elaborar uma descrição objetiva da natureza sem se referir ao processo de observação, identificou tal fenômeno como uma indeterminação; o que ficou mais conhecido como princípio da incerteza.

O princípio da incerteza está integrado à vida e é íntimo dos seres humanos, que o manipulam em razão da sua própria sobrevivência. A construção da certeza proporciona ao homem normalidade, no entanto, trata-se de uma normalidade em termos não absolutos, porque o seu contrário é uma presença acoplada.

As instituições de saúde, de educação, empresas e a legislação funcionam com base em certezas, provendo uma base geral para o seu funcionamento. A estabilidade e a continuidade são essenciais. No entanto, demasiada estabilidade ameaça a continuidade. Instituições que não se renovam caminham para a esclerose. O mesmo sucede com o ser humano. Como já foi observado anteriormente, o sujeito que não se 
renova embrutece e geralmente é excluído da dinâmica social.

Para o indivíduo e para a sociedade, o conservadorismo é tão importante para a sua manutenção e funcionamento quanto o é a renovação para a sua continuidade. A renovação constitui um risco necessário.

A escola mantém-se pelas repetições de normas, valores e sanções sociais. É a certeza. A avaliação é prevista no calendário letivo. Em geral se faz a avaliação por meio de instrumentos que aferem a reprodução do que foi ministrado em determinado período. Tal tipo de instrumento está suficientemente padronizado, e tanto os alunos como os professores sabem suas regras. Aos alunos exige-se a memorização e a reprodução de teorias e práticas vigentes. $\mathrm{O}$ professor normal é aquele que segue à risca as regras instituídas, e cujo comportamento é previsível, por estar dentro das normas.

Os alunos preferem a certeza, a repetição dos modos de dar aulas, porque já as conhecem e sabem todas as maneiras de driblar o autoritarismo do sistema. Mas a repetição não provoca entusiasmo, o encanto está na novidade.

O encanto das relações humanas reside na incerteza, mas é a certeza que nos faz funcionar como uma instituição. O homem adora a incerteza, mas é a certeza que traz a tranqüilidade, uma vida sem sustos, sem sobressaltos, como diz Demo (2000).

O conhecimento não está estagnado, ele é dinâmico. Seu desenvolvimento, ao longo da história, consolidado nos modos de pensar da humanidade, temse orientado pelo paradoxo clausura-abertura. A ciência, fenômeno marcante da era moderna, constrói e desconstrói a sua própria construção.

Hoje se vivencia um ritmo acelerado de novas descobertas científicas que, em curto tempo, são transformadas em tecnologias integradas ao funcionamento da sociedade, requerendo mão-de-obra compatível. Esse fenômeno faz com que o movimento de clausura e abertura seja um movimento constante, integrado à vida das empresas para que se mantenham competitivas.
Na ação pedagógica, todos os professores sabem que os objetivos educacionais e o planejamento didático costumam ir por água abaixo se à certeza não se integra o princípio da incerteza. A incerteza diz respeito às características dinâmicas do sujeito, do conhecimento e da sociedade humana. A certeza construída terá sempre uma janela aberta à incerteza.

O princípio da incerteza legitima o que sempre vem acontecendo na vida cotidiana e acompanha o homem desde o seu nascimento até a morte. No cotidiano, a articulação dos contrários é constantemente realizada por qualquer ser humano na tomada de decisões. Tem-se certeza de algumas coisas, porém, na tomada de decisões, tem-se de pensar na multiplicidade de fatores implicados e incertos. A incerteza é sempre uma premissa flutuante. Esse fenômeno é tão íntimo do homem que passa despercebido. Constantemente se lida com os paradoxos: certeza-incerteza, conservadorismo-inovação, ordem-desordem. O que é certo e o que é errado depende da premissa teórica. Os contrários são geradores de vida e fazem parte do processo evolutivo.

Querer moldar os alunos por meio de punições e uso de instrumentos de avaliação é colocar em prática a filosofia da pedagogia tradicional, reafirmando uma sociedade classista, elitista e excludente. E ainda mais: a educação nos moldes tradicionais (rigidez conceitual e atitudinal) não concorda com o que, no mundo contemporâneo, se exige em relação ao perfil de flexibilidade e autonomia dos trabalhadores, colocado pelo mercado de trabalho. Porém, nesse caso, objetivando a produtividade, a educação pode colocar aqueles aspectos em função do sujeito, e não somente em função da produtividade.

Apesar de a interação professor-aluno envolver a totalidade da natureza humana, os professores, em razão dos princípios da pedagogia tradicional implícitos nas estruturas do sistema e na mentalidade dominante, tendem a ignorar o processo de construção do conhecimento, suas características paradoxais, incertas, diversas e complexas. Nessa interação os professores abstraem a subjetividade; despersonalizam os alunos, os homogeneízam, priorizando a razão e a 
memória. Dá-se, então, a reprodução do sistema, um sistema educacional com orientações objetivistas, racionalistas, uniformizantes, burocratizantes, economicistas e excludentes. Orientações essas que são ainda reforçadas pelo horizonte de punição para o qual aponta a avaliação classificatória.

\section{Princípio da autopoiese}

Além dos quatro princípios já citados, mutuamente implicados (holográfico, transdisciplinaridade, complementaridade e incerteza), há ainda um outro, de suma importância para os professores, e que também faz repensar a metodologia de ensino. É o princípio da autopoiese (autofazer-se), termo empregado por Maturana e Varela (1995). Em suas pesquisas, esses pesquisadores concluíram que todo ser vivo é um sistema autopoiético, ou seja, que se auto-organiza e autoconstrói. A idéia de autopoiese relembra, imediatamente, a proposição de Paulo Freire (1997) segundo a qual o conhecimento não se transmite, se constrói.

$\mathrm{Na}$ prática do magistério, tal conceito implica recorrer a uma metodologia que estimule os alunos a produzir o próprio conhecimento. A função docente passa a ser de facilitar diálogos com os saberes, respeitando-se a diversidade e as características de cada um dos participantes do processo educativo, aceitando-se cada aluno como um ser indiviso, com estilo próprio de aprendizagem e diferente forma de resolver problemas.

O conhecimento resulta do enredamento dos aspectos do físico, do biológico e do social, considerados inseparáveis e simultâneos. Tudo o que existe no ambiente influencia o ser, que o capta e integra no processo mental de interação e construção. Nesse caso, impõe-se a necessidade de ressignificar, também, o próprio conceito de percepção.

Deve-se considerar a percepção como um fenômeno constituído por duas vias simultâneas e interagentes: de fora para dentro e de dentro para fora. Como já foi dito por Assmann (1998, p. 38), "Qualquer organismo vivo está continuamente 'presumin- do coisas' acerca do seu meio ambiente, ou seja, o organismo exerce, a todo momento, uma complexa atividade eferente (i. e. que conduz de 'dentro' para 'fora')".

Cada estrutura cerebral "negocia", "adapta" e integra no sistema neuronal a forma de compreensão dos fenômenos que a afeta, equacionando segundo suas próprias características. Assim, todo conhecimento significa reconstrução do conhecimento. Os indivíduos "ouvem" e "vêem" não somente pelos sentidos, mas também pelo cérebro, pela condição estrutural cerebral possível. Segundo Maturana e Varela (1995, p. 219), "cada pessoa diz o que diz e ouve o que ouve segundo sua própria determinação estrutural".

De acordo com a concepção tradicional, a percepção é dualística: emissor-receptor. Esse conceito de percepção fundamenta a pedagogia de transmissão de conhecimentos. A percepção é entendida como um fenômeno de uma só via: de fora para dentro. O conhecimento situa-se fora do sujeito, que precisa memorizálo para dele apropriar-se. O pressuposto aqui é que o conhecimento repassado constitui verdade indiscutível, só restando aos alunos memorizá-lo.

Essa prática educacional esvazia o encanto e o prazer de aprender, ao separar ser e saber (conseqüência da dicotomia cartesiana sujeito-objeto). O saber é objetivado, coisificado e cobrado por meio das provas. Essa prática ainda é hegemônica, principalmente nas universidades. Em virtude da estrutura fragmentária de institutos como ilhas de saberes específicos e fechados em si, os professores não costumam estar em dia com as construções na área pedagógica.

Aqueles que praticam a pedagogia tradicional acreditam (e esperam comprovar por meio das provas) que as informações repassadas em salas de aula são assimiladas integralmente pelos "bons" alunos (pedagogia bancária ou da domesticação).

$\mathrm{Na}$ apropriação do conhecimento, o sujeito, ao mobilizar suas características individuais, não mantém a fidedignidade da informação. Por isso se diz que todo conhecimento é uma reconstrução do conhecimento. Trata-se de uma atividade auto-organi- 
zativa que produz diferenças em decorrência da diversidade do meio, das relações humanas, da carga genética de cada indivíduo e da sua própria história de vida.

O ser humano aprende tendo por base conhecimentos já estruturados, não apenas conhecimentos objetivos, mas também as sensações, as emoções e as intuições. A aprendizagem emerge de dentro do sujeito cognoscente. Como indica a noção de autopoiese, o sujeito estabelece relações com o novo na produção da vida, reestruturando o seu próprio organismo. $\mathrm{O}$ novo enreda-se no velho, reestruturando as sinapses neuronais.

O ser humano é uma organização viva e contextualizada; um sistema aberto que possui uma estrutura própria de auto-regulação e dispõe de um modo particular de construção, sempre inserido no meio ecológico, com o qual interage e assume compromissos e responsabilidades.

Aprendizagem é um processo progressivo em anel retroativo-recursivo que transgride a lógica clássica, em direção a um nível cada vez mais integrado ao todo. Esse conceito de aprendizagem não visa à acumulação de conhecimentos, mas pretende que os alunos dialoguem com os conhecimentos, reestruturando-se e retendo o que é significativo. Relembrando as palavras do neurofisiologista Karl Pribram (apud Talbot, 1991), o cérebro é um holograma envolto por um universo holográfico. Aprender é uma construção pessoal, autopoiética, interagindo com os acontecimentos em volta.

Assim, educar significa levar os jovens a dialogarem com o conhecimento. Cuidar da autoreferencialidade por meio da multirreferencialidade. Cuidar da unidade por intermédio da diversidade. É um paradoxo? Certamente que sim.

\section{Considerações finais}

Ao denunciar a insuficiência dos princípios tácitos na estrutura organizacional, influenciando atitudes e um modo de pensar e ensinar em toda a comunidade educacional, a complexidade e a trans- disciplinaridade constituem um corpo teórico que possibilita o resgate do elo perdido, o sentido do conhecimento para a vida.

Um sistema conceitual que, segundo o próprio Edgar Morin (1997), responsável por essa sistematização, no momento em que é lançado ao mundo sofre o jogo das ações e interações e segue direções inesperadas, muitas vezes até contrárias às intenções dos autores. A esse jogo de ações e interações Morin chama de "ecologia da ação", o que significa que o conhecimento é dinâmico, mas também sofre o fenômeno do "reducionismo", como ocorreu, por exemplo, com a pedagogia libertadora, que se transformou em "método Paulo Freire", omitindo sua fundamentação e sendo preenchida com conceitos da pedagogia tradicional, que é o senso comum.

As teorias são construções humanas para interpretar os fenômenos da natureza e conferir sentido à existência humana. São sistemas conceituais que têm na sua essência a completude (para sua operacionalização), e também o seu contrário, a incompletude, ou seja, uma face aberta à renovação. Elas situam-se num terreno movediço, sempre sujeito a incertezas e transformações. A desagregação, o religar outra vez e o contextualizar novamente são incessantes. Enquanto houver vida no homem, esse processo é interminável. Sua sobrevivência depende dessa capacidade reorganizativa.

As teorias podem transformar-se em paradigmas que norteiam as ações humanas num dado momento histórico, porém se defasam quando seus instrumentos conceituais não mais explicam os fenômenos que emergem do desenrolar da vida no planeta. Portanto, elas serão sempre históricas, dinâmicas e provisórias.

\section{Referências bibliográficas}

ARAGÃO, Rosália Maria Ribeiro. Reflexões sobre ensino, aprendizagem, conhecimento. Revista Ciência \& Tecnologia, Piracicaba: UNIMEP, v. 7, n. 3, p. 15-17, 1993.

ARANHA, Maria Lúcia de Arruda. História da educação. São Paulo: Moderna, 1996. 
ASSMANN, Hugo. Reencantar a educação: rumo à sociedade aprendente. Petrópolis: Vozes, 1998.

BOFF, Leonardo. A águia e a galinha; uma metáfora da condição humana. Petrópolis: Vozes, 1997.

BOHM, David. Wholeness and the implicate order. London: Routledge \& KeganPaul, 1980.

BOHR, Niels. Atomic physics and human knowledge. New York: Science Editions Inc., 1961.

BRASIL. Ministério da Educação. Parâmetros curriculares nacionais: apresentação dos temas transversais. Brasília: MEC, 2001. (Ética, v. 8).

CARVALHO, Edgar Assis. Prefácio. In: GALENO, Alex; CASTRO, Gustavo de; COSTA DA SILVA, Josimey (Orgs.). Complexidade à flor da pele. São Paulo: Cortez, 2003. p. 11-15.

CONGRESSO DE LOCARNO. Que universidade para o amanhã? Em busca de uma evolução transdisciplinar da universidade. Locarno. Anais... Disponível em: $<$ http//www.redebrasileirade transdisciplinaridade.net/>. Acesso em: 10 fev. 2006.

DELEUZE, Gilles; GUATTARI, Felix. Capitalisme et schizophrénie: mille plateaux. Paris: Minuit, 1980.

DEMO, Pedro. Certeza da incerteza: ambivalência do conhecimento e da vida. Brasília: Plano, 2000.

DESCARTES, René. Discurso do método. In: René Descartes. Trad. J. Guinsburg e Bento Prado Júnior. São Paulo: Abril Cultural, 1973. p. 33-81 (Coleção Os Pensadores).

FAZENDA, Ivani. Interdisciplinaridade; um projeto em parceria. São Paulo: Loyola, 1993.

(Org.). Práticas interdisciplinares na escola. São Paulo: Cortez, 2001.

FREIRE, Paulo. A educação do futuro. $O$ Globo, Rio de Janeiro, Caderno Prosa \& Verso, 24 maio 1997.

GADOTTI, Moacyr. História das idéias pedagógicas. São Paulo: Ática, 2003.

HEISENBERG, Werner. Physics and philosophy: the revolution in modern science. New York: Harper Torcbooks, 1962.

. A parte e o todo: encontros e conversas sobre física,

filosofia, religião e política. Trad. Vera Ribeiro. Rio de Janeiro: Contraponto, 1996.

LIBÂNEO, José Carlos. Didática. São Paulo: Cortez, 1991.

. As teorias pedagógicas modernas revisitadas pelo debate contemporâneo na educação. In: LIBÃNEO, José Carlos; SANTOS, Akiko (Orgs.). Educação na era do conhecimento em rede e transdisciplinaridade. Campinas: Alínea, 2005. p. 19-63.
MACHADO, Nilson José. Epistemologia e didática: as concepções de conhecimento e inteligência e a prática docente. São Paulo: Cortez, 1999.

MATURANA, Humberto; VARELA, Francisco. A árvore do conhecimento. Campinas: Psy II, 1995.

MELLO, Maria Fernandes de. Transdisciplinaridade, uma visão emergente. Um projeto transdisciplinar. 1999. Disponível em: $<\mathrm{http}$ //www.cetrans.futuro.usp.br/gödelianos.htm>. Acesso em: 11 jun. 1999.

MORIN, Edgar. Problema epistemológico da complexidade. Portugal: Europa-América, 1983.

. Introdução ao pensamento complexo. Lisboa: Instituto Piaget, 1991.

. Complexidade e ética da solidariedade. In: CASTRO, Gustavo de et al. Ensaios de complexidade. Porto Alegre: Sulina, 1997. p. 11-20.

. O método 4. As idéias. Trad. Juremir Machado da Silva. Porto Alegre: Sulina, 1998.

. A cabeça bem feita. Repensar a reforma, reformar o pensamento. Trad. Eloá Jacobina. Rio de Janeiro: Bertrand Brasil, 2000.

(Dir.). A religação dos saberes: o desafio do século

XXI. Trad. Flavia Nascimento. Rio de Janeiro: Bertrand Brasil, 2001.

NICOLESCU, Basarab. O manifesto da transdisciplinaridade. Trad. Lúcia Pereira de Souza. São Paulo: Trion, 1999.

. Definition of transdisciplinarity. 2003. Disponível em: <http://www.interdisciplines.org/interdisciplinarity/papers/5/ 24/>. Acesso em: 15 dez. 2003.

PETRAGLIA, Izabel Cristina. Edgar Morin: a educação e a complexidade do ser e do saber. Petrópolis: Vozes, 1995.

TALBOT, Michael. O universo holográfico. Trad. Maria de Fátima S. Marques. São Paulo: Best Seller, 1991.

AKIKO SANTOS, doutora em educação pela Universidade Metodista de Piracicaba, é professora da Universidade Federal Rural do Rio de Janeiro, atuando no mestrado de educação agrícola. Publicou recentemente: "Teorias e métodos pedagógicos sob a ótica do pensamento complexo" (In: LIBÂNEO, José Carlos; SANTOS, Akiko (Orgs.). Educação na era do conhecimento em rede e transdisciplinaridade. Campinas: Alínea, 2005, p. 63-83.); Didática sob a ótica do pensamento complexo (Porto Alegre: Sulina, 2003); "Des-construindo a didática" (Revista Universida- 
de Rural, Rio de Janeiro: UFRRJ, série Ciências Humanas, v. 23, n. 1, jan./jun. 2001); "Técnicas didáticas: um novo olhar" (Revista Comunicações, ano 6, n. 1, jun. 1999). Pesquisa conjunta em desenvolvimento no Laboratório de Estudos e Pesquisas Transdisciplinares: "Mente Humana - Clausura-Abertura: a comple- mentaridade dos opostos" (http://www.ufrrj.br/leptrans). E-mail: akiko.santos@gmail.com Aprovado em outubro de 2007 
Akiko Santos

Complexidade e

transdisciplinaridade em educação: cinco princípios para resgatar o elo perdido

$\mathrm{O}$ artigo discute a potencialidade de alguns princípios, elaborados por cientistas de diferentes áreas, no resgate de um sentido do conhecimento para a vida, elo perdido com a prática de sua fragmentação. Tais princípios são: princípio holográfico (David Bohm/ Edgar Morin), princípio de complementaridade dos opostos (Niels Böhr), princípio da transdisciplinaridade (Basarab Nicolescu), princípio da incerteza (Werner Heisenberg) e princípio da autopoiese (H. Maturana e F. Varela). Esses princípios estão integrados à teoria da complexidade e transdisciplinaridade.

Palavras-chave: educação; complexidade; transdisciplinaridade

\section{Complexity and transdisciplinarity in education: five principles for rescuing the lost link}

This article discusses the potential of a number of principles, elaborated by scientists of different areas, for rescuing the meaning of knowledge for life, a link lost by the practice of fragmentation. These are the holographic principle (David Bohm/ Edgar Morin), the principle of complementarity of opposites (Niels Böhr), the principle of transdisciplinarity (Basarab
Nicolescu), the uncertainty principle

(Werner Heisenberg) and that of autopoiesis (H. Maturana e F. Varela) which are integrated in the theory of complexity and transdisciplinarity.

Key words: education; complexity; transdisciplinarity

\section{Complejidad y transdiciplinalidad} en la educación: cinco principios para rescatar el eslabón perdido

El artículo discute la potencialidad de algunos principios, elaborados por científicos de diferentes áreas, en el rescate de un sentido del conocimiento para la vida, el eslabón perdido con la práctica de su fragmentación. Estos principios son: principio holográfico

(David Bohm/Edgar Morin), principio de complementariedad de los opuestos (Niels Böhr), principio de transdiciplinalidad (Basarab

Nicolescu), principio de la incertidumbre (Werner Heisenberg) y el principio de la autopoiese $(H$. Maturana y F. Varela). Estos principios están integrados a la teoría de la complejidad y transdiciplinalidad.

Palabras claves: educación; complejidad; transdiciplinalidad 